University of Nebraska - Lincoln

DigitalCommons@University of Nebraska - Lincoln

Faculty Publications from Nebraska Center for

Materials and Nanoscience

Materials and Nanoscience, Nebraska Center for (NCMN)

August 2005

\title{
Phase transformations and thermodynamic properties of nanocrystalline FePt powders
}

\author{
J. Lyubina \\ IFW Dresden, Institute for Metallic Materials \\ O. Gutfleisch \\ IFW Dresden, Institute for Metallic Materials \\ Ralph Skomski \\ University of Nebraska-Lincoln, rskomski2@unl.edu \\ K.-H. Müller \\ IFW Dresden, Institute for Metallic Materials \\ L. Schultz \\ IFW Dresden, Institute for Metallic Materials
}

Follow this and additional works at: https://digitalcommons.unl.edu/cmrafacpub

Part of the Nanoscience and Nanotechnology Commons

Lyubina, J.; Gutfleisch, O.; Skomski, Ralph; Müller, K.-H.; and Schultz, L., "Phase transformations and thermodynamic properties of nanocrystalline FePt powders " (2005). Faculty Publications from Nebraska Center for Materials and Nanoscience. 4.

https://digitalcommons.unl.edu/cmrafacpub/4

This Article is brought to you for free and open access by the Materials and Nanoscience, Nebraska Center for (NCMN) at DigitalCommons@University of Nebraska - Lincoln. It has been accepted for inclusion in Faculty Publications from Nebraska Center for Materials and Nanoscience by an authorized administrator of DigitalCommons@University of Nebraska - Lincoln. 


\title{
Phase transformations and thermodynamic properties of nanocrystalline FePt powders
}

\author{
J. Lyubina*, O. Gutfleisch*, R. Skomskił, K.-H. Müller*, and L. Schultz* \\ * IFW Dresden \\ + Department of Physics and Astronomy \\ Institute for Metallic Materials \\ P.O. Box 270016 \\ D-01171 Dresden, Germany \\ Center for Materials Research and Analysis \\ University of Nebraska-Lincoln \\ Lincoln, NE 68588, USA
}

Submitted October 2004; accepted 21 April 2005; available online 23 May 2005; published August 2005.

\begin{abstract}
The solid state reactions and structural evolution in nanocrystalline FePt powders during mechanical ball milling at $77 \mathrm{~K}$ and subsequent annealing have been investigated. Above $310^{\circ} \mathrm{C}$ the formation of $\mathrm{L} 1_{0}$ FePt is observed. As the milling time increases, the enthalpy evolved during the transformations is reduced, whereas the corresponding activation energy increases. For accelerating the ordering process a fine lamellar structure of $\mathrm{Fe}$ and $\mathrm{Pt}$ is favourable.
\end{abstract}

Keywords: Mechanical milling, X-ray diffraction (XRD), Rietveld method, Differential scanning calorimetry (DSC), Ordering, $\mathrm{L1}_{0}$ phase

\section{Introduction}

The chemically ordered tetragonal $\mathrm{L}_{0}$ FePt phase has attracted much attention as a material for special permanent magnet applications and, more recently, for ultra-high density magnetic recording [1]. The interest in $\mathrm{L1}_{0} \mathrm{FePt}$ is a consequence of its excellent intrinsic magnetic properties $\left(K_{1}=6.6 \mathrm{MJ} \mathrm{m}^{-3}, J_{\mathrm{s}}=1.43 \mathrm{~T}, T_{\mathrm{c}}=750 \mathrm{~K}\right.$ [2] $)$, as well as high ductility and good corrosion resistance. Several approaches are used to obtain ordered $\mathrm{Ll}_{0}$ phase [3]. It can be formed by annealing of the disordered face-centered cubic (fcc) (A1) phase [2], [4] and [5]. In the thin film-form, the $\mathrm{L} 1_{0}$ FePt phase can be directly prepared by deposition onto heated substrates [6]. Ordered FePt thin films have been prepared as well by the subsequent annealing of multilayers produced by sequential deposition of separate Fe and Pt layers having thickness in the order of several nanometers [7]. Nanocrystalline FePt powders with a coercivity up to $1 \mathrm{~T}$ can also be prepared by mechanical alloying of elemental powders at $77 \mathrm{~K}$ followed by annealing at moderate temperatures [8] and [9]. The mechanisms of phase formation and ordering (i.e. continues or discontinues) differ depending on the approach used to obtain the $\mathrm{L} 1_{0}$ phase [5], [6], [9], [10] and [11]. In the present work, we investigate structural transformations occurring upon milling and subsequent annealing of the FePt powders. An improved understanding of thermodynamics and phase formation in nanocrystalline FePt should be equally valuable for other nanoparticulate FePt systems.

\section{Experimental}

For the preparation of equiatomic FePt, mixtures of elemental $\mathrm{Fe}$ and $\mathrm{Pt}$ powders with a purity of $99.9 \%$ and a particle size less than $80 \mu \mathrm{m}$ were mechanically ballmilled at liquid nitrogen and room temperature for $1-$ $7 \mathrm{~h}$ in a Misuni vibration mill. Heat treatment of the asmilled powders was carried out in the temperature range of $350-550^{\circ} \mathrm{C}$ under argon atmosphere. The structure of the as-milled and annealed powders was investigated by X-ray diffraction (Philips X'Pert diffractometer equipped with a diffracted beam monochromator) using $\mathrm{Co}_{-} \mathrm{K}_{\alpha}$ radiation. Rietveld refinement (X'Pert Plus software) was used to determine the phase composition, lattice constants and order parameter. Average crystallite size $\langle D\rangle$ and root mean square (rms) strain $\langle e\rangle$ were determined by a modified Williamson-Hall analysis [12]. The line profile parameters were extracted from the Rietveld refinement, in the assumption of a pseudo-Voigt profile, and corrected for the instrumental broadening. As a standard reference material, $\mathrm{a} \mathrm{LaB}_{6}$ powder specimen has been used. The microstructure of the FePt powders was investigated by means of field emission gun scanning electron microscopy (FEGSEM LEO1530) equipped with energy dispersive X-ray (EDX) analysis. The thermal behaviour was examined by differential scanning calorimetry (DSC 404C Netzsch) over the temperature range of $50-1000{ }^{\circ} \mathrm{C}$ with heating rates of $5-40^{\circ} \mathrm{C} / \mathrm{min}$ under flowing argon. 


\section{Results}

\subsection{Milling of FePt}

Fig. 1 shows the X-ray diffraction patterns of the $\mathrm{Fe}-\mathrm{Pt}$ powders prior to and after milling at liquid nitrogen temperature for different time intervals. Considerable changes in the phase composition and microstructure are observed after short milling times. Initially sharp X-ray diffraction lines are appreciably broadened after only $1 \mathrm{~h}$ of milling. In order to separate the contributions to the overall breadth from crystallite size and lattice strain the modified WilliamsonHall analysis, the so-called "average size-strain" method of Langford [12] was applied. The effect of stacking faults to the peak broadening was not considered in this study. It has to be noted, however, that no peak displacements produced by deformation faulting were detected for the FePt powders studied. The "average size-strain" plot for the $1 \mathrm{~h}$ milled Fe/ Pt powder yields $\langle D\rangle$ of about $29 \mathrm{~nm}$ for Pt and $43 \mathrm{~nm}$ for $\alpha$ Fe, i.e. substantial reduction in the grain sizes compared to the starting microcrystalline powders is observed. The root mean square (rms) strain $\langle e\rangle$ for Pt and $\alpha$-Fe was estimated to be about $0.16 \%$ and $0.21 \%$, respectively. Further milling results in a reduction of the grain sizes of $\operatorname{Pt}(\langle D\rangle \approx 23 \mathrm{~nm})$ and $\alpha-\mathrm{Fe}(\langle D\rangle \approx 17 \mathrm{~nm})$ and an increase of the rms strain to $0.27 \%$ and $0.55 \%$, respectively. High resolution scanning electron microscopy (SEM) investigation reveals that the microstructure of the powder milled for $2 \mathrm{~h}$ is a lamellar structure of the constituent elements having a thickness of about 20-300 nm (Fig. 2). The fine contrast within the Pt lamellae confirms the nanocrystalline nature of the powders. Moreover, Rietveld refinement reveals the presence of the fcc (A1) FePt phase having dimensions of $\sim 5 \mathrm{~nm}$ in the powders milled for $2 \mathrm{~h}$. Thus, alloying starts to occur at this milling stage. The following phase contents were determined for this powder: $\alpha$-Fe ( $\sim 31$ vol.\%), Pt ( 36 vol.\%) and $\mathrm{A} 1 \mathrm{FePt}(\sim 33$ vol.\%).

Increase of the milling time to $5 \mathrm{~h}$ yields a further refined lamellae structure of the constituent elements (not shown). The $\alpha-\mathrm{Fe}$ and $\mathrm{Pt}$ fractions are reduced, whereas the amount of A1 FePt increases (Fig. 3). The grain sizes of $\alpha$-Fe and Pt reduce to $\sim 7$ and $9 \mathrm{~nm}$, respectively. However, this minimum grain size does not correspond to the maximum strain: rms strain of $\alpha-\mathrm{Fe}$ and Pt reduces to about $0.05 \%$. That is, the rms strain increases rapidly at the first stage of the milling, but for longer milling times it decreases. A similar behaviour was observed for low energy ball-milled pure metals [13]. The grain size and lattice strain of the A1 FePt phase after milling for $5 \mathrm{~h}$ were determined to be about $15 \mathrm{~nm}$ and $0.65 \%$, respectively.

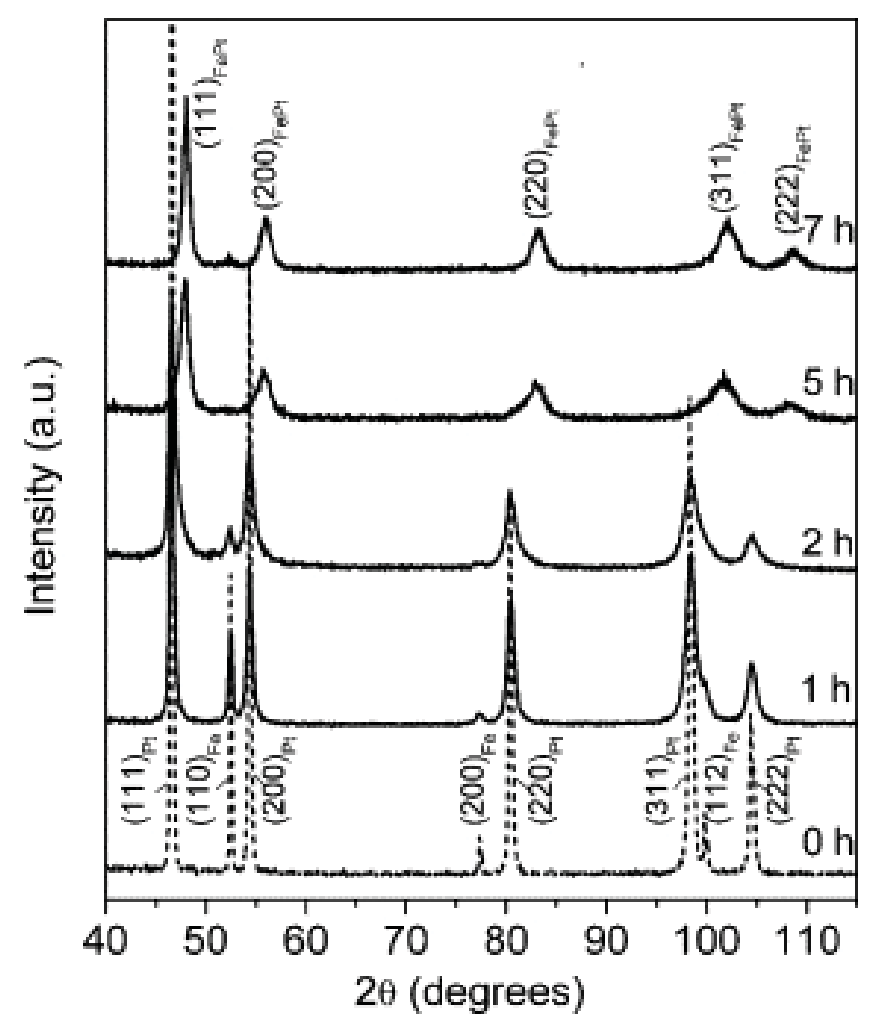

Fig. 1. X-ray diffraction patterns of the FePt powders prior to and after milling for various times at liquid nitrogen temperature.

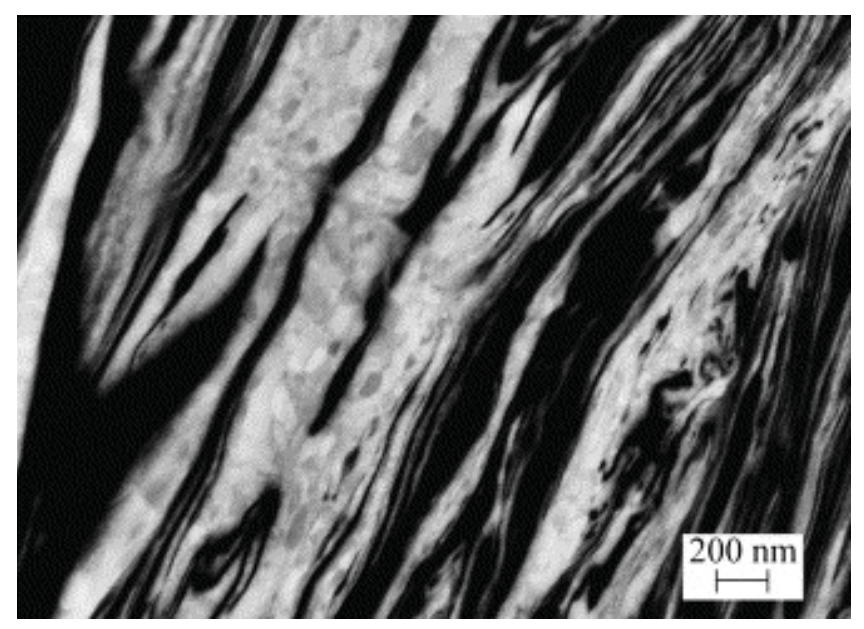

Fig. 2. High resolution SEM image (backscattered electron mode) of the FePt powder milled at liquid nitrogen temperature for $2 \mathrm{~h}$. 
After $7 \mathrm{~h}$ of milling at liquid nitrogen temperature A1 FePt fraction reaches $84.4(7)$ vol.\%, the rest being $\alpha-F e$. The grain size of the A1 phase is almost unchanged, although the lattice strain decreases to $0.49 \%$. The lattice constant of the A1 FePt phase formed by $7 \mathrm{~h}$ of milling was determined to be $a=0.38196(2) \mathrm{nm}$. SEM investigation revealed that the observed $\alpha-\mathrm{Fe}$ is due to the iron from the balls and vial walls, which is usually observed in powders milled with steel as a grinding medium [14].

For comparison, milling at room temperature was also performed and X-ray analysis indicates that the formation of the A1 FePt phase occurs faster. However, the crystallite sizes are increased and the yield of the powder after room temperature milling is extremely low due to the cold welding of the material onto the milling media.

\subsection{Thermal behaviour of the FePt powders milled at $77 \mathrm{~K}$}

As an example, Fig. 4 shows DSC traces for the $\mathrm{Fe}_{50} \mathrm{Pt}_{50}$ powders milled for 2, 5 and $7 \mathrm{~h}$. Rietveld refinement of X-ray data of the samples annealed to temperatures before and after the transformation confirms that the exothermic reaction is due to the formation and ordering of new phases. With increasing milling time, the minimum of the transformation peak $\left(T_{\mathrm{m}}\right)$ shifts towards lower temperatures: from about $440{ }^{\circ} \mathrm{C}$ for $2 \mathrm{~h}$ milled powder to $367^{\circ} \mathrm{C}$ for $7 \mathrm{~h}$ milled powder. It has to be noted, that the onset of the transformation appears essentially at the same temperature of about $310(4){ }^{\circ} \mathrm{C}$ independent of milling time. The transformation peak becomes narrower with increase of milling time: its full width at half maximum decreases from about $120^{\circ} \mathrm{C}\left(2 \mathrm{~h}\right.$ milled) to $56{ }^{\circ} \mathrm{C}(7 \mathrm{~h}$ milled). The amount of heat $\Delta H$ evolved during the transformations, determined from the area under the peaks, decreases correspondingly from about $110(20) \mathrm{J} / \mathrm{g}$ to $70(9) \mathrm{J} /$ $\mathrm{g}$ and $55(2) \mathrm{J} / \mathrm{g}$ as the milling time increases from 2 to 5 and $7 \mathrm{~h}$. Isothermal DSC measurements at $290{ }^{\circ} \mathrm{C}$, i.e. below the onset temperature of the transformations, have shown a signal that only decayed with time.

For the analysis of the DSC curves, the Kissinger method [15] was employed using heating rates $\beta$ between 5 and $40{ }^{\circ} \mathrm{C} / \mathrm{min}$. By using the linear relationship $\ln \left(T_{\mathrm{m}}^{2} / \beta\right)=E_{\mathrm{a}} / k_{\mathrm{B}} T_{\mathrm{m}}$, it is possible to obtain values for the activation energy $E_{\mathrm{a}}$ of the processes involved in the transformations, where $T_{\mathrm{m}}$ is a temperature of the transformation peak and $k_{\mathrm{B}}$ is the Boltzmann's constant. The corresponding Kissinger plot is shown in Fig. 5. The obtained activation energies were found to increase with milling time from $1.03(8) \mathrm{eV}$ for $2 \mathrm{~h}$ milled powder to 1.24(11) and 1.45(10) eV for the powders milled for 5 and $7 \mathrm{~h}$, respectively.

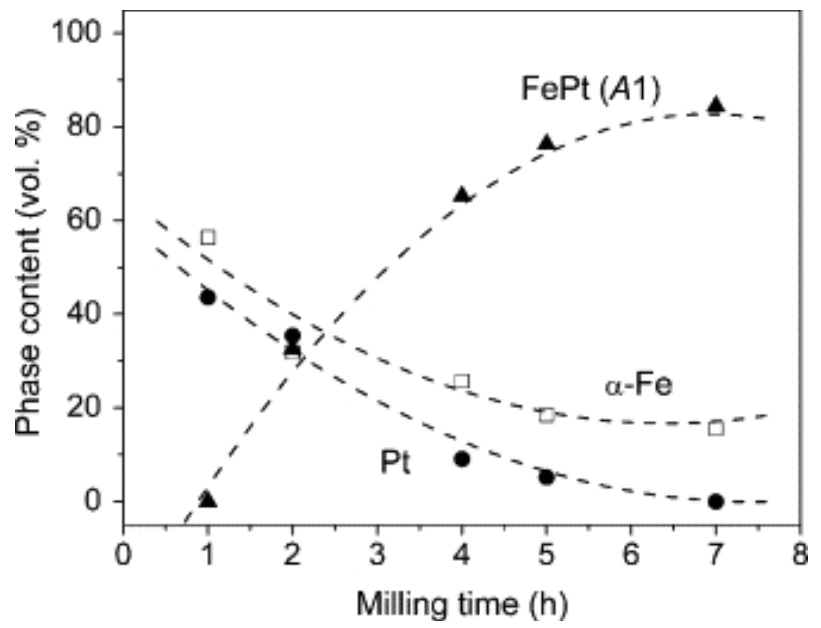

Fig. 3. Phase composition of the FePt powders milled at liquid nitrogen temperature in dependence on milling time.

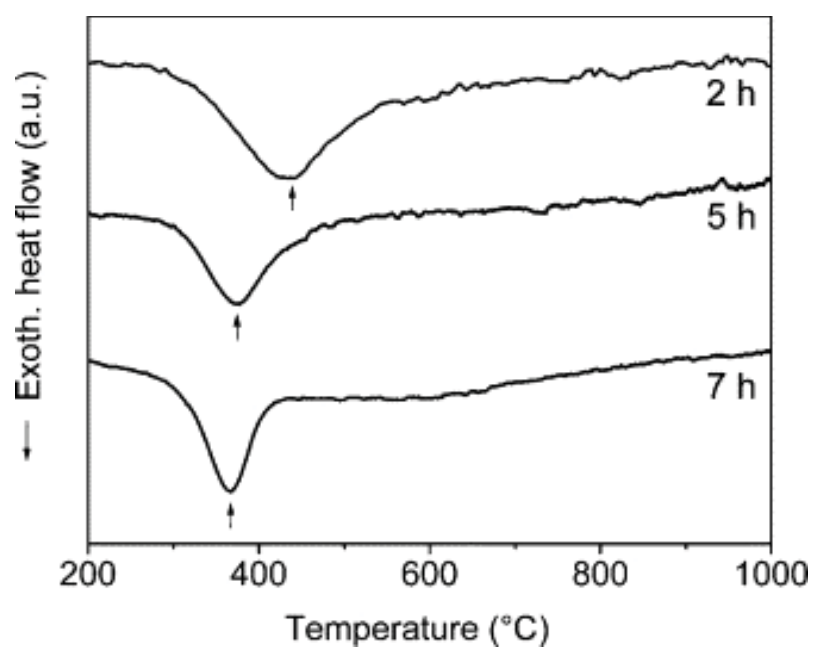

Fig. 4. DSC traces for the FePt powders milled for 2, 5 and $7 \mathrm{~h}$ (heating rate $10 \mathrm{~K} / \mathrm{min}$ ).

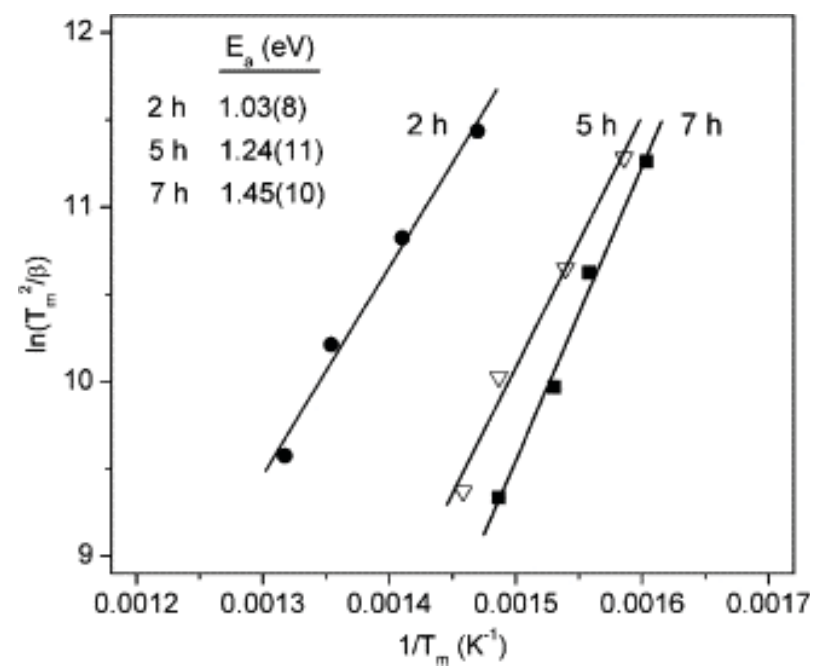

Fig. 5. Kissinger plot for the minimum of the transformation peaks for FePt powders milled for 2, 5 and $7 \mathrm{~h}$. 


\subsection{Structural analysis of the milled and annealed FePt powders}

In order to obtain information on structural changes induced by heat treatment the isothermally annealed and subsequently quenched FePt powders were investigated using quantitative X-ray diffraction Rietveld analysis and high resolution SEM. Annealing was carried out at temperatures in the vicinity of the DSC transformation peaks and above $\left(350-550^{\circ} \mathrm{C}\right)$ for a series of times between $10 \mathrm{~min}$ and $48 \mathrm{~h}$.

Heat treatment of the $2 \mathrm{~h}$ milled FePt powder at $450{ }^{\circ} \mathrm{C}$ induces an immediate formation and ordering of $\mathrm{L}_{0} \mathrm{FePt}$ and two additional $\mathrm{Fe}_{3} \mathrm{Pt}\left(\mathrm{Ll}_{2}\right)$ and $\mathrm{FePt}_{3}\left(\mathrm{Ll}_{2}\right)$ phases. After a short heat treatment (e.g. after $10 \mathrm{~min}$ ), unreacted $\alpha$-Fe (7 vol.\%) and $\mathrm{Pt}$ (5 vol.\%), as well as A1 FePt (13 vol.\%) are present. $\mathrm{L}_{0} \mathrm{FePt}_{2} \mathrm{Fe}_{3} \mathrm{Pt}$ and $\mathrm{FePt}_{3}$ fractions are equal to 53,6 and 15 vol.\%, respectively. With increasing annealing time the amount of residual $\mathrm{Fe}$ and $\mathrm{Pt}$ is reduced and no elemental $\mathrm{Fe}$ and $\mathrm{Pt}$ are observed upon annealing at $450{ }^{\circ} \mathrm{C}$ for $16 \mathrm{~h}$ and longer. At the same time, $\mathrm{L}_{0} \mathrm{FePt}$ fraction increases and the $\mathrm{Fe}_{3} \mathrm{Pt}$ and $\mathrm{FePt}_{3}$ fractions are reduced. The Rietveld refinement of $\mathrm{X}$-ray diffraction patterns (not shown here) of the FePt powders annealed at $450{ }^{\circ} \mathrm{C} / 48 \mathrm{~h}$ yields the following phase contents: about 84 vol. $\%$ of $\mathrm{L}_{0} \mathrm{FePt}$, 8 vol. $\%$-A1 FePt, 5 vol. $\%-\mathrm{FePt}_{3}$ and 3 vol. $\%$-Fe ${ }_{3} \mathrm{Pt}$.

Increased annealing temperature promotes faster reaction rates. For instance, after annealing for $10 \mathrm{~min}$ at 500 and $550{ }^{\circ} \mathrm{C}$ the amounts of the $\mathrm{L} 1_{0} \mathrm{FePt}$ phase are 62(1) vol.\% and 71.1(7) vol.\%, respectively. The higher the annealing temperature, the smaller is the amount of the $\mathrm{Fe}_{3} \mathrm{Pt}$ and $\mathrm{FePt}_{3}$ phases. However, these phases are still present in the samples annealed for $48 \mathrm{~h}$. For the annealing conditions studied, the maximum FePt $\left(\mathrm{L1}_{0}\right)$ content was about 96(1) vol.\% after heat treatment at $550{ }^{\circ} \mathrm{C} / 48 \mathrm{~h}$, the rest being $\mathrm{A} 1 \mathrm{FePt}\left(\sim 2\right.$ vol.\%) and $\mathrm{L}_{2} \mathrm{FePt}_{3}(\sim 2$ vol.\%).

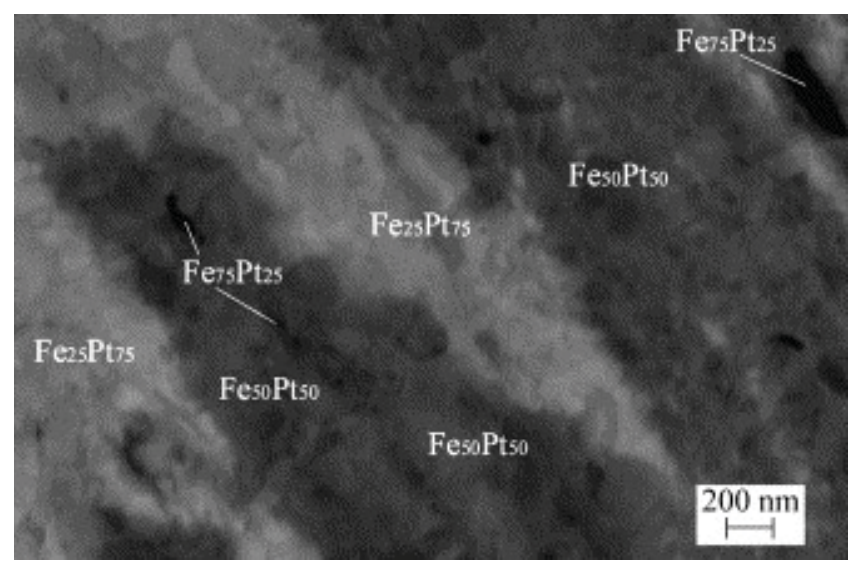

Fig. 6. High resolution SEM (backscattered electron mode) image of the FePt powder milled for $2 \mathrm{~h}$ and annealed at $450{ }^{\circ} \mathrm{C} / 48 \mathrm{~h}$.
The following lattice parameters of the $\mathrm{L} 1_{0} \mathrm{FePt}$ phase in the heat treated FePt powders were determined from the Rietveld analysis: $a=0.3858(2) \mathrm{nm}$ and $c=0.3716(3) \mathrm{nm}(c /$ $a \approx 0.964$ ). Lattice constants of the A1 phase were equal to $a=0.3820(3) \mathrm{nm}$. No significant changes in the lattice parameter of the $\mathrm{L1}_{0}$ and $\mathrm{A} 1 \mathrm{FePt}$ phases were observed in dependence on the annealing conditions studied.

Rietveld analysis was also employed for the investigation of site occupations in the $\mathrm{L}_{0} \mathrm{FePt}$ phase and the determination of the $\mathrm{L} 1_{0}$ FePt order parameter: $S=r_{\mathrm{Pt}}+r_{\mathrm{Fe}}-1$, where $r_{\mathrm{Pt}(\mathrm{Fe})}$ is the fraction of $\mathrm{Pt}(\mathrm{Fe})$ sites occupied by the correct atom [16]. When the order is perfect, the order parameter $S$ reaches unity, while for a completely random atom arrangement $S$ is equal to zero. The order parameter of the $\mathrm{L}_{0} \mathrm{FePt}$ phase in the heat-treated FePt powders was found to be approximately 0.9 , independent of annealing conditions. Thus, heat treatment of the powders milled for $2 \mathrm{~h}$ at liquid nitrogen temperature results in the formation of the chemically highly ordered $\mathrm{L} 1_{0}$ FePt phase.

The high resolution SEM micrograph of the FePt powder annealed at $450{ }^{\circ} \mathrm{C}$ for $48 \mathrm{~h}$ (Fig. 6) shows that the microstructure preserves a lamellar character after annealing. Three types of compositional contrast can be distinguished. Bright layers have the stoichiometry of $\mathrm{Fe}_{25} \mathrm{Pt}_{75}$. They are surrounded by $\mathrm{Fe}_{50} \mathrm{Pt}_{50}$ layers, followed by a layer of $\mathrm{Fe}_{75} \mathrm{Pt}_{25}$ (darkest contrast). The interfaces between the layers are sharp. The high resolution SEM image reveals as well that the size of the crystallites within the lamellae is substantially smaller than the lamellae thickness.

To determine the average crystallite size of the $\mathrm{L} 1_{0} \mathrm{FePt}$ phase, the "average size-strain" method was applied. Fig. 7 shows the dependence of the $\mathrm{L} 1_{0}$ FePt grain size on annealing time at different temperatures. With increasing annealing time a comparatively slow grain growth is observed. The grain growth, however, is more pronounced at $550{ }^{\circ} \mathrm{C}$. Heat treatment at this temperature for $48 \mathrm{~h}$ results in a grain size

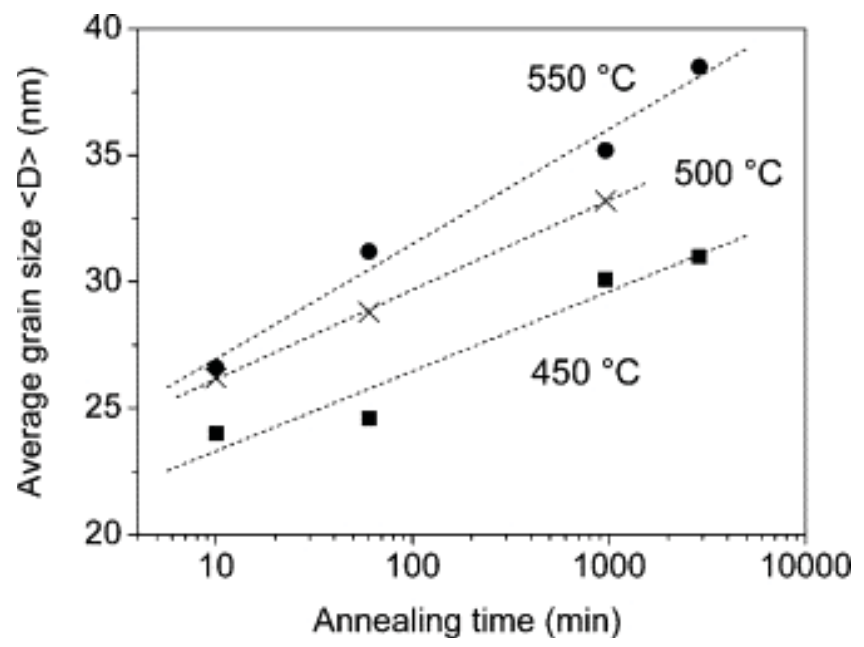

Fig. 7. Evolution of crystallite size of $\mathrm{L}_{0}$ FePt upon annealing of FePt powders (milled for $2 \mathrm{~h}$ at $77 \mathrm{~K}$ ). 
of about $39 \mathrm{~nm}$, which is noticeably higher than that of the powder annealed at $450{ }^{\circ} \mathrm{C}(\langle D\rangle \approx 30 \mathrm{~nm})$. The rms strain is in the range of $0.11-0.15 \%$. In all the studied FePt powders, no peculiar broadening of the superstructure reflections relative to the fundamental reflections was detected, i.e. no indication of the presence of the antiphase domains in the $\mathrm{L}_{0}$ phase was observed.

Heat treatment at $350{ }^{\circ} \mathrm{C}$ of the $\mathrm{FePt}$ powders milled for $7 \mathrm{~h}$ induces the $\mathrm{A} 1 \mathrm{FePt} \rightarrow \mathrm{L}_{0}$ FePt transformation. A substantial amount of the A1 FePt phase $(67 \%)$ is transformed after only $10 \mathrm{~min}$ of annealing at this temperature. The transformed $\mathrm{L} 1_{0}$ fraction increases with annealing time and reaches about $89 \%$ after heat treatment at $350{ }^{\circ} \mathrm{C}$ for $16 \mathrm{~h}$. The order parameter of the $\mathrm{L} 1_{0} \mathrm{FePt}$ phase was found to increase from $S=0.72$ (2) to $S=0.87$ (3) for the powders annealed for $10 \mathrm{~min}$ and $16 \mathrm{~h}$, correspondingly. Along with the disordered and ordered FePt phases, $\alpha$-Fe was detected in the annealed powders. Its fraction $(\sim 15 \mathrm{vol} . \%)$ is constant with annealing time, i.e. it is not consumed during the transformation. Considering that 15 vol. $\%$ of $\alpha-F e$ was already present in the as-milled powders, it can be concluded that the observed $\alpha-F e$ is due to the additional iron from the milling media.

At $450{ }^{\circ} \mathrm{C}$, the transformation of the $\mathrm{A} 1$ phase into $\mathrm{L} 1_{0}$ $\mathrm{FePt}$ phase in the $7 \mathrm{~h}$ milled FePt powders is essentially finished after $10 \mathrm{~min}$ of annealing. The amount of $\mathrm{L} 1_{0}$ FePt reaches about 78 vol.\%, A1 FePt and $\alpha$-Fe fractions are equal to 7 and 15 vol.\%, respectively. Again, assuming that $\alpha-\mathrm{Fe}$ is essentially milling media debris, one obtains that about $91 \%$ of $\mathrm{A} 1 \mathrm{FePt}$ is consumed during the $\mathrm{A} 1 \rightarrow \mathrm{L} 1_{0}$ transformation. Further increase of annealing time does not lead to substantial changes in the phase composition. However, order parameter of the $\mathrm{L} 1_{0} \mathrm{FePt}$ phase slightly increases from 0.92(1) to 0.97(2) in the powders annealed for $10 \mathrm{~min}$ and $48 \mathrm{~h}$, respectively. Average crystallite size of $\mathrm{L}_{0}$ FePt was found to slowly increase from 23 to $30 \mathrm{~nm}$ upon increasing the annealing time from $10 \mathrm{~min}$ to $48 \mathrm{~h}$.

In order to compare $\mathrm{L}_{0}$ fractions transformed during annealing, the $5 \mathrm{~h}$ milled $\mathrm{FePt}$ powders were heat treated at $450{ }^{\circ} \mathrm{C}$ for $48 \mathrm{~h}$. The following phase composition was determined: $86.7(7)$ vol. $\%$ of $\mathrm{L1}_{0} \mathrm{FePt}, 3.4(5)$ vol.\% of A1 FePt and 9.9(7) vol.\% of $\alpha$-Fe. Assuming that about 10 vol. $\%$ of $\alpha-\mathrm{Fe}$ is from milling media, the transformed $\mathrm{L1}_{0} \mathrm{FePt}$ fraction is estimated to be $97 \%$. The order parameter of the formed $\mathrm{L} 1_{0}$ phase is about $0.98(2)$.

\section{Discussion}

The evolution of structure observed during ball milling of elemental $\mathrm{Fe}$ and $\mathrm{Pt}$ powders at liquid nitrogen temperature is consistent with the mechanism of alloying in a system with two different ductile components [14]. The yield of the powder is much higher after milling at $77 \mathrm{~K}$ com- pared to that at room temperature due to the minimised cold welding of the powder onto the milling media. When milling is performed at $77 \mathrm{~K}$, the formation of the disordered A1 FePt phase starts later compared to room temperature milling. This allows to adjust the microstructure of the FePt powders and, depending on the aim, to finish with either a lamellar structure of the constituent elements (multilayertype), disordered A1 FePt phase or an intermediate structure, consisting of fine lamellae of $\mathrm{Fe}$ and $\mathrm{Pt}$, with the $\mathrm{A} 1$ FePt phase formed at their interfaces [17].

Heat treatment of the as-milled powders induces combined solid state reactions that take place in solids in which thermodynamic equilibrium is approached by more than one elementary reaction [18]. It leads simultaneously to the decrease of defect density, nucleation and growth of the new phases concurrent with the ordering process. Comparing the formation of the $\mathrm{L} 1_{0}$ phase starting from $\mathrm{A} 1$ or lamellar precursors, one should not overlook a principal difference in the mechanisms of the phase formation. In a recent study [9], we have shown that on annealing $\mathrm{Fe}_{100-x} \mathrm{Pt}_{x}(x \neq 50)$ powders with a lamellar structure it is energetically more favourable to form highly ordered FePt $\left(\mathrm{L}_{0}\right)$ and additional $\mathrm{Fe}_{3} \mathrm{Pt}\left(\mathrm{Ll}_{2}\right)$ or $\mathrm{FePt}_{3}\left(\mathrm{Ll}_{2}\right)$ phases, rather than nonequiatomic FePt $\left(\mathrm{L}_{0}\right)$, as it could have been expected according to the equilibrium $\mathrm{Fe}-\mathrm{Pt}$ phase diagram. Here it is observed that neither the lattice constants nor the order parameter of the $\mathrm{L} 1_{0} \mathrm{FePt}$ phase are changed substantially once the phase is formed. However, if the initial powders predominantly have a disordered A1 structure, heat treatment induces ordering of the A1 FePt phase into $\mathrm{L}_{0}$ FePt. In the $7 \mathrm{~h}$ milled FePt powders, the order parameter $S$ of the $\mathrm{L}_{0}$ phase formed as a result of $\mathrm{Al} \mathrm{FePt} \rightarrow \mathrm{Ll}_{0}$ FePt transformation increases gradually with increasing annealing time and temperature.

The peak of the transformations observed in the constant heating rate DSC curves is shifted towards lower temperatures with increase of milling time. This can be attributed first, to the finer lamellae and smaller grain size of the phases, favouring diffusion along grain boundaries and second, to the alloying of the elements on an atomic level. In the isothermal DSC measurements at $290{ }^{\circ} \mathrm{C}$ no distinct peak was detected. Rietveld analysis of the samples after the measurements reveals the presence of the $\mathrm{L} 1_{0} \mathrm{FePt}$ and, in the case of the $2 \mathrm{~h}$ milled powder, additional $\mathrm{Fe}_{3} \mathrm{Pt}$ and $\mathrm{FePt}_{3}$ phases. The apparent absence of a peak in the isothermal DSC measurements has been ascribed to transformations starting with fast nucleation from random positions followed by a comparatively slow diffusion-controlled growth [19] and [20]. Slow growth rates could be supported, for instance, by the data shown in Fig. 7. Interdiffusion between the constituent elements, which has already occurred during the milling, may provide the necessary mixing of atoms, thus favouring rapid nucleation of the new phases. This could explain the appearance of the transformation onset at almost 
the same temperature of $310{ }^{\circ} \mathrm{C}$ in the powders milled for different times.

For the $7 \mathrm{~h}$ milled powder, consisting mainly of the A1 FePt phase, no long distance diffusion is required to form the $\mathrm{L} 1_{0}$ phase and consequently the reaction is completed at lower temperatures. The highest apparent activation energy of $1.45(10) \mathrm{eV}$ was observed for this powder. The amount of heat $\Delta H \approx 155 \mathrm{~J} / \mathrm{g}$ evolved during the transformation was smallest, implying that less energy was stored compared to the powders milled for 2 and $5 \mathrm{~h}$. The lowest activation energy $E_{\mathrm{a}}=1.03(8) \mathrm{eV}$ and highest enthalpy change of about $110 \mathrm{~J} / \mathrm{g}$ was obtained for the powders milled for $2 \mathrm{~h}$, i.e. for the lamellar structure of $\mathrm{Fe}$ and $\mathrm{Pt}$ with a $\sim 5 \mathrm{~nm}$ thick $\mathrm{A} 1$ $\mathrm{FePt}$ at their interfaces. An additional driving force resulting from the concentration gradient presence could be expected for this powder. However, higher temperatures would be needed for the completion of the reactions, since to form the new phases atoms should diffuse over longer distances.

When comparing the $\mathrm{L} 1_{0}$ fractions transformed after annealing at $450{ }^{\circ} \mathrm{C} / 48 \mathrm{~h}$ for the $7 \mathrm{~h}\left(E_{\mathrm{a}}=1.45(10) \mathrm{eV}\right)$ and $5 \mathrm{~h}\left(E_{\mathrm{a}}=1.24(11) \mathrm{eV}\right)$ milled powders, it turns out that the $\mathrm{L1}_{0}$ amount is higher in the latter case and apparently no additional phases, like $\mathrm{Fe}_{3} \mathrm{Pt}$ or $\mathrm{FePt}_{3}$ are formed. Therefore, to achieve larger amounts of highly ordered $\mathrm{L} 1_{0} \mathrm{FePt}$, a fine lamellar structure is favourable.

The observed activation energies are substantially lower than the activation energy of $3.1 \mathrm{eV}$ for interdiffusion in single-crystalline A1 FePt [21]. As shown in Ref. [20], activation energies for grain growth, phase formation and ordering in nanocrystalline materials are lower than for bulk diffusion and are of the same order of magnitude as those for fast diffusion along defects, such as dislocations or grain boundaries. Therefore, one could expect that in the studied $\mathrm{FePt}$ powders diffusion over the grain boundaries is a determining factor for the phase transformations, ordering and grain growth. The obtained activation energies are comparable to those found for the $\mathrm{A} 1 \rightarrow \mathrm{L} 1_{0}$ transformation in sputter deposited FePt films [10] and [11].

\section{Conclusions}

Nanocrystalline FePt powders were prepared by mechanical ball milling at liquid nitrogen temperature. Depending on the milling time, either a lamellar (multilayertype) structure of Fe and $\mathrm{Pt}$, or $\mathrm{A} 1 \mathrm{FePt}$ or an intermediate structure, consisting of fine lamellae of $\mathrm{Fe}$ and $\mathrm{Pt}$ with A1 $\mathrm{FePt}$ formed at their interfaces was obtained. On annealing at temperatures just above $310^{\circ} \mathrm{C}$, combined solid state reactions become activated resulting in the formation of $\mathrm{L}_{0}$ $\mathrm{FePt}$ phase and, in the case of the $2 \mathrm{~h}$ milled powder, additional $\mathrm{Fe}_{3} \mathrm{Pt}$ and $\mathrm{FePt}_{3}$ phases. The amount of heat evolved during the transformations, decreases from about 110 to $70 \mathrm{~J} / \mathrm{g}$ and $55 \mathrm{~J} / \mathrm{g}$ as the milling time increases from 2 to 5 and $7 \mathrm{~h}$. Diffusion over the grain boundaries is supposed to be the determining factor for the phase transformations, ordering and grain growth. The transformation activation energy of 1.03(8) eV obtained for the lamellar structure of the constituent elements was found to be lower than that for the disordered $\mathrm{A} 1 \rightarrow$ ordered $\mathrm{L}_{0}$ transformation $(1.45(10) \mathrm{eV})$. It is concluded that in order to accelerate the ordering process a fine lamellar structure should be favoured.

\section{References}

[1] S. Sun, C.B. Murray, D. Weller, L. Folks and A. Moser, Science 287 (2000), p. 1989.

[2] O.A. Ivanov, L.V. Solina, V.A. Demshina and L.M. Magat, Phys Metals Metallogr 35 (1973), p. 92.

[3] A. Cebollada, R.F.C. Farrow and M.F. Toney In: H.S. Nalwa, Editor, Magnetic Nanostructures, American Scientific, Stevenson Ranch, CA (2002), p. 93.

[4] K. Watanabe and H. Masumoto, Trans Jpn Inst Met 24 (1983), p. 627.

[5] R.A. Ristau, K. Barmak, L.H. Lewis, K.R. Coffey and J.K. Howard, J Appl Phys 86 (1999), p. 4527.

[6] A. Cebollada, D. Weller, J. Sticht, G.R. Harp, R.F.C. Farrow and R.F. Marks et al., Phys Rev B 50 (1994), p. 3419.

[7] J.P. Liu, C.P. Luo, Y. Liu and D.J. Sellmyer, J Appl Phys Lett 72 (1998), p. 483.

[8] J. Lyubina, O. Gutfleisch, K.H. Müller, L. Schultz and N.M. Dempsey, J Appl Phys 95 (2004), p. 7474.

[9] J. Lyubina, O. Gutfleisch, K.H. Müller and L. Schultz, J Magn Magn Mater 290-291 (2005), p. 547.

[10] F.E. Spada, F.T. Parker, C.L. Platt and J.K. Howard, J Appl Phys 94 (2003), p. 5123.

[11] K. Barmak, J. Kim, S. Shell, E.B. Svedberg and J.K. Howard, Appl Phys Lett 80 (2002), p. 4268.

[12] Langford JI. In: Prince E, Stalick JK, editors. Proc Int Conf: Accuracy in powder diffraction II. Washington, DC: NIST Special Publication No. 846. US Government Printing Office, 1992. p. 110.

[13] D. Oleszak and P.H. Shingu, J Appl Phys 79 (1996), p. 2975.

[14] C. Suryanarayana, Prog Mater Sci 46 (2001), p. 1.

[15] H.E. Kissinger, Anal Chem 29 (1957), p. 1702

[16] B.E. Warren, X-ray diffraction, Dover, NY (1990).

[17] O. Gutfleisch, J. Lyubina, K.H. Müller and L. Schultz, Adv Eng Mater 7 (2005), p. 208.

[18] E. Hornbogen, Metall Trans A 10A (1979), p. 947.

[19] C. Michaelsen, G. Lucadamo and K. Barmak, J Appl Phys 80 (1996), p. 6689.

[20] L. Battezzati, P. Pappalepore, F. Durbiano and I. Gallino, Acta Mater 47 (1999), p. 1901.

[21] A. Kushida, K. Tanaka and H. Numakura, Mater Trans JIM 44 (2003), p. 59. 